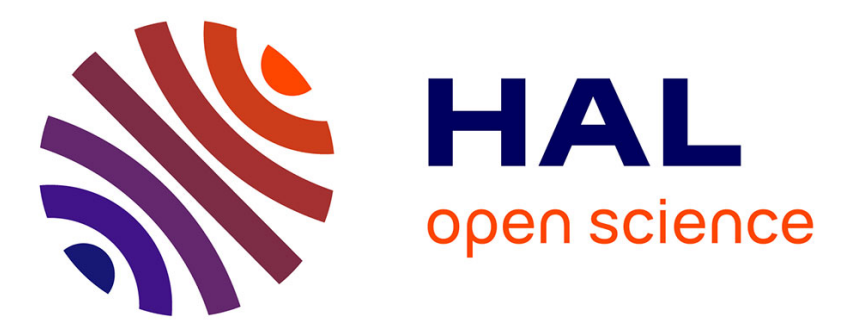

\title{
Epitaxial Zn 3 N 2 thin films by molecular beam epitaxy: Structural, electrical, and optical properties
} \author{
P. John, M. Al Khalfioui, C. Deparis, A. Welk, C. Lichtensteiger, R. Bachelet,
} G. Saint-Girons, H. Rotella, M. Hugues, M. Grundmann, et al.

\section{- To cite this version:}

P. John, M. Al Khalfioui, C. Deparis, A. Welk, C. Lichtensteiger, et al.. Epitaxial Zn 3 N 2 thin films by molecular beam epitaxy: Structural, electrical, and optical properties. Journal of Applied Physics, 2021, 130 (6), pp.065104. 10.1063/5.0057307 . hal-03319215

\section{HAL Id: hal-03319215 \\ https://hal.science/hal-03319215}

Submitted on 20 Oct 2021

HAL is a multi-disciplinary open access archive for the deposit and dissemination of scientific research documents, whether they are published or not. The documents may come from teaching and research institutions in France or abroad, or from public or private research centers.
L'archive ouverte pluridisciplinaire HAL, est destinée au dépôt et à la diffusion de documents scientifiques de niveau recherche, publiés ou non, émanant des établissements d'enseignement et de recherche français ou étrangers, des laboratoires publics ou privés. 


\section{Epitaxial $Z n_{3} N_{2}$ thin films by molecular beam epitaxy: structural, electrical and optical properties}

P. John ${ }^{1}$, M. Al Khalfioui ${ }^{1}$, C. Deparis ${ }^{1}$, A. Welk ${ }^{2}$, C. Lichtensteiger ${ }^{3}$, R. Bachelet ${ }^{4}$, G. Saint-Girons ${ }^{4}$, H. Rotella ${ }^{1}$, M. Hugues ${ }^{1}$, M. Grundmann ${ }^{2}$, and J. Zúñiga-Pérez ${ }^{1{ }^{*}}$

${ }^{1}$ Université Côte d'Azur, CNRS, CRHEA, Rue Bernard Gregory, 06560 Valbonne, France

${ }^{2}$ Universität Leipzig, Felix-Bloch-Institut für Festkörperphysik, Linnéstraße 5, 04103 Leipzig, Germany

${ }^{3}$ DQMP, University of Geneva, 24 Quai Ernest Ansermet, Geneva 4, 1211, Switzerland

${ }^{4}$ Université de Lyon, Institut des Nanotechnologies de Lyon (UMR5270/CNRS), Ecole Centrale de Lyon, 36 avenue Guy de Collongue, F-69134 Ecully Cedex, France

*e-mail: jzp@crhea.cnrs.fr

\section{ABSTRACT}

Single-crystalline $\mathrm{Zn}_{3} \mathrm{~N}_{2}$ thin films have been grown on $\mathrm{MgO}(100)$ and YSZ (100) substrates by plasma-assisted molecular beam epitaxy. Depending on the growth conditions the film orientation can be tuned from (100) to (111). For each orientation, $x$-ray diffraction and reflection high-energy electron diffraction are used to determine the epitaxial relationships and to quantify the structural quality. Using high temperature x-ray diffraction, the $Z n_{3} N_{2}$ linear thermal expansion coefficient is measured with an average of $(1.5 \pm 0.1) \cdot 10^{-5} \mathrm{~K}^{1}$ in the range of 300 to $700 \mathrm{~K}$. The $\mathrm{Zn}_{3} \mathrm{~N}_{2}$ films are found to be systematically n-type and degenerate, with carrier concentrations of $10^{19}$ to $10^{21} \mathrm{~cm}^{-3}$ and electron mobilities ranging from 4 to $388 \mathrm{~cm}^{2} V^{1} \mathrm{~s}^{-1}$. Low-temperature Hall effect measurements show that ionized impurity scattering is the main mechanism limiting the mobility. The large carrier densities lead to measured optical band-gaps in the $1.05 \mathrm{eV}$ to $1.37 \mathrm{eV}$ range due to Moss-Burstein band filling, with an extrapolated value of $0.99 \mathrm{eV}$ for the actual band-gap energy. 


\section{INTRODUCTION}

Since the 1990s there has been strong interest to establish the epitaxial growth and the fundamental properties of group III-nitrides, due to their application in numerous commercial devices, such as transistors, ${ }^{1}$ LEDs $^{2}$ and Lasers. ${ }^{3}$ On the contrary, there has been only little research on group IInitrides: their epitaxy is not well established and some of their basic physical properties not yet measured.

In the 2000s, the II-nitride material $Z_{3} \mathrm{~N}_{2}$ got into the focus of research, because of the strong interest to fabricate $\mathrm{p}$-type doped $\mathrm{ZnO}$, which would have led to a breakthrough in $\mathrm{ZnO}$-based optoelectronic devices. In this context, several attempts were made to achieve $\mathrm{p}$-ZnO by (partial) oxidation of $\mathrm{Zn}_{3} \mathrm{~N}_{2}{ }^{4-12}$ or by fabricating $\mathrm{ZnO}: \mathrm{N}$ from $\mathrm{Zn}_{3} \mathrm{~N}_{2}$ targets, as demonstrated by pulsed laser ablation. ${ }^{13}$ This also led to increased research activity on $\mathrm{Zn}_{3} \mathrm{~N}_{2}$ itself, including first demonstrations of $\mathrm{Zn}_{3} \mathrm{~N}_{2}$ in the field of thin film transistors (TFTs). ${ }^{14-22}$

Although some band-gap studies on $\mathrm{Zn}_{3} \mathrm{~N}_{2}$ estimated values of $2.9-3.4 \mathrm{eV},{ }^{14,16,23,24}$ most of the recent studies and theoretical calculations, including photoluminescence measurements, find values in the 0.8-1.5 eV range. ${ }^{10,15,25-38}$ The reason for this large discrepancy lies probably in the tendency of $\mathrm{Zn}_{3} \mathrm{~N}_{2}$ to oxidize in ambient conditions, ${ }^{34,39}$ which could lead to a strong overestimation of the band-gap energy, as masked by the presence of $\mathrm{ZnO}$ (with a band-gap in the order of $3.3 \mathrm{eV}^{40}$ ). However, even in recent literature, the reported values display a large spread. This is, at least partially, due to poor crystalline quality, which can complicate the determination of the actual band-gap energy due to the introduction of numerous energy levels within the band-gap. Indeed, most of previous studies cover amorphous or polycrystalline $Z_{3} N_{2}$ thin films and only a few reports are on epitaxial $Z n_{3} N_{2}$. Furthermore, it seems to be difficult to fabricate non-degenerate $Z n_{3} N_{2}$ thin films with carrier concentrations below $10^{19} \mathrm{~cm}^{-3}, 27,33,34,37,41,42$ which lead to a Burstein-Moss shift of the absorption edge that could have caused an overestimation of the band-gap as well. ${ }^{43,44}$ Nevertheless, $\mathrm{Zn}_{3} \mathrm{~N}_{2}$ films show generally quite large electron mobilities in the range of $100 \mathrm{~cm}^{2} / \mathrm{Vs}$, probably due to the low 
reported electron effective mass of $0.08 \mathrm{~m}_{0},{ }^{42}$ making it an attractive candidate as active layer for TFTs.

As mentioned before there are only very few reports on epitaxial thin films, obtained either by molecular beam epitaxy (MBE) or by sputtering. In the case of MBE, a first report in 2006 showed that $Z n_{3} N_{2}$ (111) was grown on a-plane sapphire ${ }^{45}$, while a more recent work shows on the contrary that $\mathrm{Zn}_{3} \mathrm{~N}_{2}(100)$ grows on both $\mathrm{MgO}(100)$ and a-plane sapphire substrates ${ }^{36}$. In the case of epitaxial growth by sputtering, $\mathrm{Zn}_{3} \mathrm{~N}_{2}(100)$ was achieved on $\mathrm{YSZ}(100)^{42}$. While some of these studies investigated the epitaxial relationships between the substrate and the overgrown $\mathrm{Zn}_{3} \mathrm{~N}_{2}$ thin film, ${ }^{42,45}$ none of them contains a detailed structural analysis of the thin films and none of them determined the correlation between crystallographic orientation and growth conditions.

In this contribution we report the epitaxial growth of $\mathrm{Zn}_{3} \mathrm{~N}_{2}$ (exhibiting the cubic anti-bixbyite structure ${ }^{46}$ ) by plasma-assisted MBE on MgO (100) and YSZ (100). We demonstrate the ability to control the film orientation by varying the growth conditions and we identify the epitaxial relationships of each configuration. Furthermore, we provide a full picture of the films' structural, electrical and optical properties as a function of their growth conditions, determined by in-depth $\mathrm{x}$ ray diffraction (XRD), Hall effect and UV-vis-NIR transmission measurements, respectively. Finally, thanks to the use of high-temperature XRD, we report for the first time the thermal expansion coefficient of $\mathrm{Zn}_{3} \mathrm{~N}_{2}$, an important parameter in epitaxial growth since it allows to evaluate the lattice mismatch between film and substrate at the actual growth temperature.

\section{EXPERIMENTAL}

$\mathrm{Zn}_{3} \mathrm{~N}_{2}$ thin films were grown by plasma-assisted MBE in a Riber EPINEAT system, equipped with two Zn (99.9999\%) effusion cells and a radio-frequency plasma cell, operated at $400 \mathrm{~W}$ to crack molecular nitrogen gas (99.9999 \%). The base pressure of the MBE system prior to growth was in the order of $10^{-9}$ Torr. Growth was performed on $10 \times 20 \mathrm{~mm}^{2} \mathrm{MgO}(100)$ substrates purchased from CRYSTAL and on $10 \times 20 \mathrm{~mm}^{2}$ YSZ (100) (yttria-stabilized zirconia, $9.5 \mathrm{~mol} \% \quad \mathrm{Y}_{2} \mathrm{O}_{3}$ ) substrates 
purchased from CrysTec. The substrates were prepared by rapid thermal annealing for $2 \mathrm{~min}$ at $1150^{\circ} \mathrm{C}$ under oxygen atmosphere to obtain atomically flat surfaces. Prior to growth, the substrates were systematically exposed to nitrogen plasma and $\mathrm{Zn}$ flux at $300{ }^{\circ} \mathrm{C}$ in the MBE chamber, leading to an improvement of their surface crystallinity as detected by reflection high-energy electron diffraction (RHEED). The increased quality of the substrate surface led, in turn, to an improved crystallinity of the subsequently grown $\mathrm{Zn}_{3} \mathrm{~N}_{2}$ thin films. The growth temperature was varied between $50{ }^{\circ} \mathrm{C}$ and $250^{\circ} \mathrm{C}$, as monitored using a thermocouple placed close to the substrate holder. In-situ optical reflectivity and RHEED were used to evaluate the growth rate and surface crystallinity, respectively.

The structural properties of the $\mathrm{Zn}_{3} \mathrm{~N}_{2}$ films were characterized with XRD and x-ray reflectivity (XRR) using a Panalytical X'Pert Pro MRD system with $\mathrm{Cu} \mathrm{K}_{\alpha 1}$ radiation (1.54056 ̊̊). High-resolution measurements (HRXRD) were done using a crystal analyzer in triple axis configuration, where the diffracted beam undergoes three Ge(220) reflections before entering the detector. Hightemperature XRD measurements were performed under pressurized air in a Rigaku Smartlab diffractometer, equipped with a closed Anton Paar chamber, also using $\mathrm{Cu} \mathrm{K}_{\alpha 1}$ radiation, and the sample height was realigned after every temperature step.

Electrical properties were measured at room temperature by the van der Pauw method using a home-built Hall effect system equipped with an electromagnet at a magnetic field of $0.8 \mathrm{~T}$. Temperature dependent Hall effect measurements of selected samples were done with a Physical Property Measurement System (PPMS) from Quantum Design Europe in the range of $30 \mathrm{~K}$ to $300 \mathrm{~K}$ and a magnetic field of up to $9 \mathrm{~T}$.

Finally, ultraviolet-visible-near infrared (UV-vis-NIR) transmission measurements were employed to evaluate the optical properties of the $\mathrm{Zn}_{3} \mathrm{~N}_{2}$ films using a PerkinElmer Lambda 19 spectrometer, equipped with a photomultiplier tube and a PbS detector for UV-vis and NIR measurements, respectively. 


\section{RESULTS}

\section{A. $\mathrm{Zn}_{3} \mathrm{~N}_{2}$ GROWTH: EPITAXIAL ORIENTATION TUNABILITY}

The effect of substrate temperature on the film orientation was investigated by growing $Z_{3} N_{2}$ thin films in a temperature range of $50{ }^{\circ} \mathrm{C}$ to $250{ }^{\circ} \mathrm{C}$ under $\mathrm{N}$-rich conditions. The detailed growth conditions of the samples, including their thicknesses and growth rates are given in Table I. Figure 1 (a) shows the $2 \theta / \omega$ scans of $\sim 40 \mathrm{~nm}$ thick $Z \mathrm{n}_{3} \mathrm{~N}_{2}$ films on $\mathrm{MgO}(100)$ substrates. Note that the XRD patterns were recorded with a fully open detector in order to detect any possible contribution of parasitic phases. Besides the $\mathrm{MgO}(200)$ substrate peak, only a very weak signal at the $\mathrm{Zn}_{3} \mathrm{~N}_{2}(400)$ position is detected for the sample grown at $50{ }^{\circ} \mathrm{C}$ (sample A). Combined with RHEED observations, which show only faint circles atop a strong continuous background at the end of the growth (image not displayed), this points towards a very low-quality microstructure compatible with small crystalline domains within an amorphous matrix. Increasing the substrate temperature leads to crystallization of the thin films: In sample $B$, grown at $100{ }^{\circ} \mathrm{C}$, the $\mathrm{Zn}_{3} \mathrm{~N}_{2}(400)$ reflection dominates the XRD pattern, indicating that the majority of the grains follow the [100] growth direction, although a low-intensity $Z_{3} N_{2}$ (222) peak is also present. When increasing the growth temperature further, the (100) intensity diminishes gradually and growth along the [111] direction becomes dominant, as observed for the samples $\mathrm{D}$ and $\mathrm{E}$, grown at $200^{\circ} \mathrm{C}$ and $250^{\circ} \mathrm{C}$, respectively.
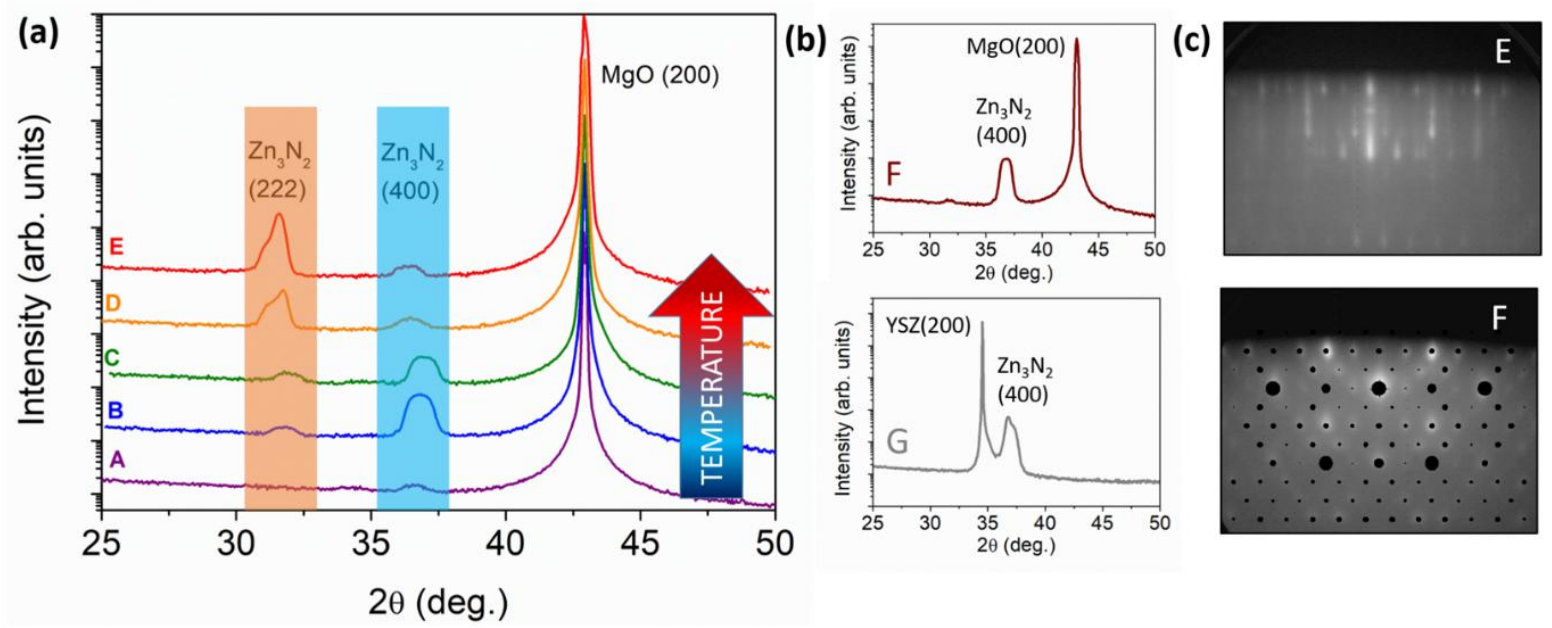

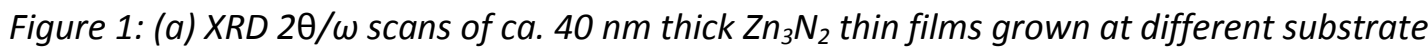
temperatures, measured with a fully open detector. The letters $A$ to $G$ refer to the different growth 


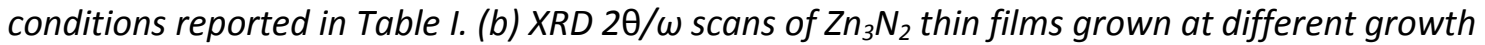
conditions compared to (a), top, and on a different susbstrate, bottom. The growth conditions are reported in Table I. (c) RHEED patterns taken along the MgO [011] direction of the samples $E$ (top) and $F$ (bottom). The black dots in sample $F$ denote a simulated diffraction pattern along $Z n_{3} N_{2}$ [011]. Note that the RHEED of sample $E$ was recorded at the initial growth stage, while the one of sample $F$ was recorded after the $\mathrm{Zn}_{3} \mathrm{~N}_{2}$ growth.

Interestingly, the growth on $\mathrm{MgO}(100)$ starts always with (111)-oriented $\mathrm{Zn}_{3} \mathrm{~N}_{2}$. Indeed, even in samples where both orientations are obtained (e.g. sample E), no traces of $\mathrm{Zn}_{3} \mathrm{~N}_{2}(100)$ can be detected by RHEED in the initial growth stages (see Figure 1 (c), sample E). The RHEED pattern is streaky and very similar to the one obtained for the growth of $\mathrm{Mg}_{3} \mathrm{~N}_{2}(111)$ on $\mathrm{MgO}(100)$, being isostructural to $\mathrm{Zn}_{3} \mathrm{~N}_{2} \cdot{ }^{47,48}$ However, as the growth proceeds in the (111)-oriented films, the growth direction evolves continuously towards [100], as indicated by the presence of additional spots in the RHEED pattern (not shown here). This instability might be associated to the surface energy of cubic (100) and (111) planes, the (100) planes being thermodynamically favorable. Thus, the initial nucleation of $Z n_{3} N_{2}$ (111) might point towards an effect of the film-substrate interaction, which is overcome by thermodynamics for sufficiently thick films. This is in agreement with previous MBEgrown $\mathrm{Zn}_{3} \mathrm{~N}_{2}$ on $\mathrm{MgO}(100)$, where (100)-oriented films were exclusively obtained. ${ }^{36}$ Above $250{ }^{\circ} \mathrm{C}$, no growth was observed, indicating significant $\mathrm{Zn}$ re-evaporation that is not compensated by the impinging Zn flux.

Table l: Growth conditions of the $Z n_{3} N_{2}$ samples.

\begin{tabular}{ccccccc}
\hline Sample & Substrate & $\begin{array}{c}\text { Growth temperature } \\
\left({ }^{\circ} \mathrm{C}\right)\end{array}$ & $\begin{array}{c}\text { Zn flux } \\
\left(10^{-7} \text { Torr }\right)\end{array}$ & $\begin{array}{c}\text { Nitrogen flow } \\
(\mathrm{sccm})\end{array}$ & $\begin{array}{c}\text { Thickness XRR } \\
(\mathrm{nm})\end{array}$ & $\begin{array}{c}\text { Growth rate } \\
(\mathrm{nm} / \mathrm{min})\end{array}$ \\
\hline $\mathrm{A}$ & $\mathrm{MgO}(100)$ & 50 & 2.2 & 1.0 & 48 & 0.69 \\
$\mathrm{~B}$ & $\mathrm{MgO}(100)$ & 100 & 2.2 & 1.0 & 44 & 0.69 \\
$\mathrm{C}$ & $\mathrm{MgO}(100)$ & 150 & 2.2 & 1.0 & 38 & 0.60 \\
$\mathrm{D}$ & $\mathrm{MgO}(100)$ & 200 & 2.2 & 1.0 & 37 & 0.59 \\
$\mathrm{E}$ & $\mathrm{MgO}(100)$ & 250 & 2.2 & 1.0 & 41 & 0.54 \\
$\mathrm{~F}$ & $\mathrm{MgO}(100)$ & 100 & 2.8 & 0.85 & 65 & 1.08
\end{tabular}


While the $\mathrm{Zn}_{3} \mathrm{~N}_{2}$ (111) nucleation on $\mathrm{MgO}(100)$ seems unavoidable, one can accelerate the swing towards (100) by changing the growth conditions, which is consistent with this orientation being thermodynamically driven. This can be achieved by changing the $\mathrm{Zn} / \mathrm{N}$ ratio towards more $\mathrm{Zn}$-rich conditions, as demonstrated for sample F in Figure 1(b). The associated RHEED pattern (taken along the $\mathrm{MgO}$ [011] direction) can be perfectly simulated with diffraction from only $\mathrm{Zn}_{3} \mathrm{~N}_{2}(011)$, as shown by the black dots that are superimposed to the pattern in Figure 1(c), sample F. Furthermore, if for a certain application the presence of (111) grains was unacceptable, one can achieve fully epitaxial $\mathrm{Zn}_{3} \mathrm{~N}_{2}(100)$ thin films on YSZ (100), as illustrated by sample $\mathrm{G}$ in the bottom of Figure 1(b). To our knowledge this has not been reported so far by MBE. The RHEED of this sample (not shown here) exhibits the same pattern as that of $\mathrm{Zn}_{3} \mathrm{~N}_{2}$ (100) on $\mathrm{MgO}$ (100) (sample F).

\section{B. $\mathrm{Zn}_{3} \mathrm{~N}_{2}$ EPITAXY: EPITAXIAL RELATIONSHIPS AND STRUCTURAL QUALITY}

To confirm the epitaxial character of the $\mathrm{Zn}_{3} \mathrm{~N}_{2}$ thin films and determine their epitaxial relationships with respect to the substrates, we performed $\phi$ scans on asymmetric $Z n_{3} N_{2}(440)$ planes, where $\phi$ is the azimuthal angle around an axis perpendicular to the sample surface. The $\phi$ scan of $Z n_{3} N_{2}(111)$ on $\mathrm{MgO}(100)$ (sample E) is presented in Figure 2(a). In principle, only three (440) peaks are expected for a $360^{\circ}$-rotation of $\phi$, as the growth direction is [111]. Nevertheless, 12 peaks are experimentally observed. To explain this fact one has to consider the substrate and epi-layer rotational symmetries as examined in general by Grundmann et al.: ${ }^{49,50}$ due to the four-fold symmetry of the MgO (100) substrate (see Figure 2(c)) and the three-fold symmetry of the $\mathrm{Zn}_{3} \mathrm{~N}_{2}$ (111) layer, four energetically equivalent epitaxial twin domains exist for the (111) epi-layer as schematically illustrated in Figure 2(E). This structure leads consequently to 12 peaks in the XRD $\phi$ scan. The epitaxial relationships for $Z n_{3} N_{2}$ (111) || MgO (100) are hence

$$
[1 \overline{1} 0] \mathrm{Zn}_{3} \mathrm{~N}_{2} \|[011] \mathrm{MgO}
$$


$[11 \overline{2}] \mathrm{Zn}_{3} \mathrm{~N}_{2} \|[01 \overline{1}] \mathrm{MgO}$,

plus the three epitaxial twin domains obtained by rotating the $\mathrm{Zn}_{3} \mathrm{~N}_{2}$ by $90^{\circ}, 180^{\circ}$ and $270^{\circ}$ around the [111] axis. We observed the same epitaxial relation for the iso-structural $\mathrm{Mg}_{3} \mathrm{~N}_{2}(111)$ on $\operatorname{MgO}(100)^{47,48}$.

The $\phi$ scan of $\mathrm{Zn}_{3} \mathrm{~N}_{2}(100)$ on YSZ (100) (sample G) is presented in Figure 2(b). This time only four peaks are observed for the (440) reflection, as expected for a (100)-oriented layer on a (100)oriented substrate (see Figure 2(c) for the substrate's $\phi$ scan). Consequently, the epitaxial relationships are given by

$$
\begin{aligned}
& {[100] \mathrm{Zn}_{3} \mathrm{~N}_{2} \|[100] \mathrm{YSZ}} \\
& {[011] \mathrm{Zn}_{3} \mathrm{~N}_{2} \|[011] \mathrm{YSZ}}
\end{aligned}
$$

Note that the same epitaxial relationships were found for sample $\mathrm{F}\left(\mathrm{Zn}_{3} \mathrm{~N}_{2}(100)\right.$ on $\mathrm{MgO}(100)$, $\phi$ scan not shown here), as confirmed by the RHEED pattern of sample $F$ in Figure 1.
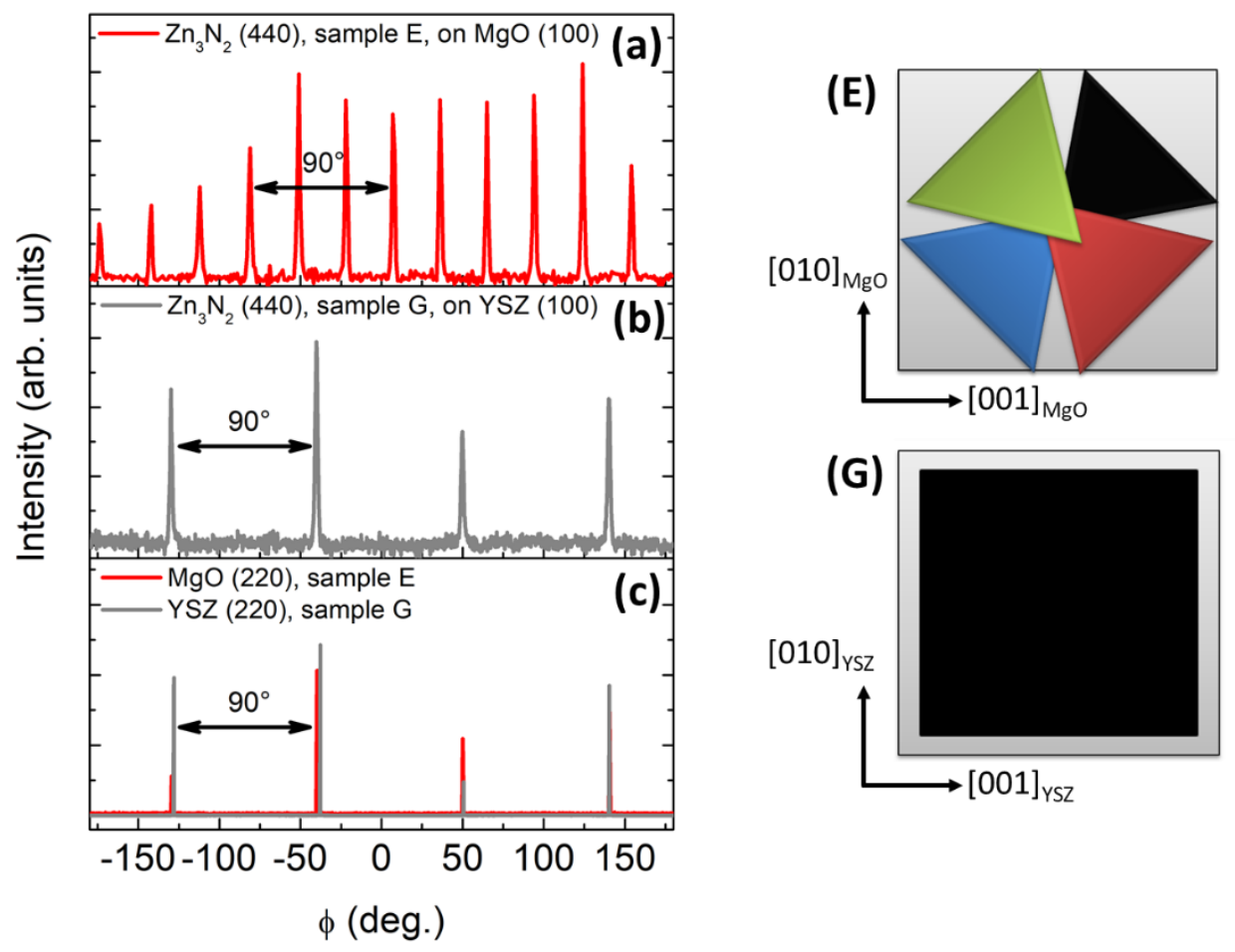

Figure 2: XRD $\phi$ scans on asymmetric $Z n_{3} N_{2}$ (440) planes of (a) $Z n_{3} N_{2}$ (111) on MgO (100) (sample E) and (b) $\mathrm{Zn}_{3} \mathrm{~N}_{2}$ (100) on YSZ (100) (sample G), measured with a fully open detector. (c) ф scans on the (220) reflections from the respective substrates. $(E)$ and $(G)$ show the resulting schematic epitaxial relationships of the samples $E$ and $G$, respectively. 
In order to evaluate the structural quality of the different $\mathrm{Zn}_{3} \mathrm{~N}_{2}$ thin films (grown with two different orientations, i.e. (111) and (100), and on two different substrates, MgO (100) and YSZ (100)), we performed HRXRD on the symmetric $Z n_{3} N_{2}$ reflections. The high-resolution $2 \theta / \omega$ scan of $Z n_{3} N_{2}(111)$ grown on $\mathrm{MgO}(100)$ (sample E) is presented in Figure 3(a). The (222) main peak is surrounded by finite size interference fringes, revealing a high crystalline $x$-ray coherence along the growth direction. This interference pattern can be simulated and used to precisely determine the average film thickness as well as the out-of-plane lattice parameter. The theoretical diffraction pattern (considering perfect crystalline coherence and no surface roughness) is given by ${ }^{51}$

$$
I(\theta)=F_{h k l}^{2} \frac{\sin ^{2}\left(2 \pi n d_{h k l} \sin \theta / \lambda\right)}{\sin ^{2}\left(2 \pi d_{h k l} \sin \theta / \lambda\right)}
$$

where $\theta$ is the Bragg angle, $d_{h k l}$ is the interplanar distance of the $(h k l)$ planes, $F_{h k l}$ the corresponding structure factor and $n$ the total number of stacked $(h k l)$ planes leading to the diffraction pattern. As seen in Figure 3(a) the oscillations surrounding the (222) main peak show a strong asymmetry, with higher intensity at lower $2 \theta$ angles, which indicates an in-plane strain (and/or compositional) gradient along the growth direction. ${ }^{51,52}$ Lichtensteiger $^{53}$ developed a software allowing to reproduce this asymmetry by inserting a $d_{h k l}$ in Equation (1) that changes gradually as a function of thickness with the following functional dependence

$$
d_{h k l}=\mathrm{A} e^{-N / B}+C,
$$

where $N$ is the running unit cell number and $A, B$ and $C$ are fitting parameters.

For sample $\mathrm{E}$, a good agreement between experiment and simulation is achieved, with an average $d_{222}$ of $2.826 \pm 0.001 \AA$ (literature value of fully relaxed $\mathrm{Zn}_{3} \mathrm{~N}_{2}(222): 2.820 \AA^{46}$ ). The larger out-ofplane lattice spacing compared to the literature value indicates the presence of a global in-plane compressive strain in the layer. Furthermore, a thickness of $142 \pm 1$ unit cells $(40.1 \pm 0.3 \mathrm{~nm}$ ) could be extracted, consistent with the thickness of $41 \pm 2 \mathrm{~nm}$ obtained from XRR (see Table I). The $d_{222}$ 
lattice spacing as a function of thickness extracted from the simulation is shown in the inset of Figure 3(a). The in-plane compressive strain is strongest close to the film-substrate interface and diminishes as the thickness increases. This is consistent with the lattice parameter mismatch between the $\mathrm{MgO}$ substrate and the $\mathrm{Zn}_{3} \mathrm{~N}_{2}$ epi-layer taking into account the epitaxial relationships shown in Figure 2(E). The calculated anisotropic in-plane strains are $+0.54 \%$ along $\mathrm{Zn}_{3} \mathrm{~N}_{2}[11 \overline{2}]$ and $+16 \%$ along $\mathrm{Zn}_{3} \mathrm{~N}_{2}$ [11̄0], considering a domain phase matching condition of two MgO unit cells for one $\mathrm{Zn}_{3} \mathrm{~N}_{2}$ cell. Thus, the substrate imposes its smaller lattice to the nucleating layer $Z n_{3} N_{2}$, as observed also in the iso-structural $\mathrm{Mg}_{3} \mathrm{~N}_{2}$ (111) on $\mathrm{MgO}(100){ }^{47,48}$
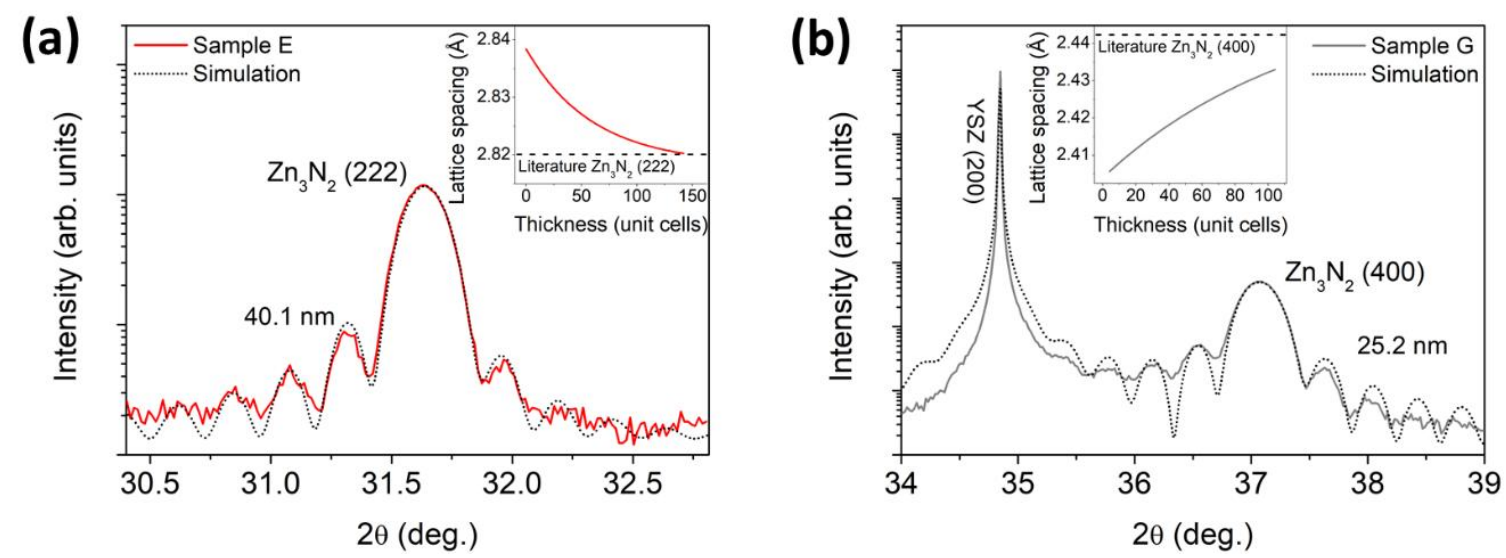

Figure 3: High-resolution 2 $\theta / \omega$ scans on the symmetric reflections of (a) sample $E$ around $Z n_{3} N_{2}(222)$ and (b) sample $G$ around $\mathrm{Zn}_{3} \mathrm{~N}_{2}$ (400). The simulations using the Equations (1) and (2) are indicated as black, dotted lines. The insets in (a) and (b) show the resulting $Z n_{3} N_{2}(222)$ and (400) depth-dependent lattice spacings, respectively. Note that the curves were measured with a crystal analyzer detector.

The high-resolution $2 \theta / \omega$ scan around the symmetric (400) reflection of sample $G\left(Z_{3} \mathrm{~N}_{2}(100)\right.$ grown on YSZ (100)) is presented in Figure 3(b). Finite size interference oscillations are observed in this case too, revealing again a high crystalline $x$-ray coherence along the growth direction and enabling to extract a thickness of $104 \pm 1$ unit cells $(25.2 \pm 0.2 \mathrm{~nm})$, consistent with the thickness of $25 \pm 1 \mathrm{~nm}$ obtained from XRR (see Table I). The average $d_{400}$ extracted was $2.420 \pm 0.001 \AA$ (literature value of fully relaxed $Z_{3} N_{2}$ (400): $2.442 \AA^{46}$ ), indicating this time the presence of a global and strong tensile strain in the layer. Indeed, the lattice parameter mismatch between the YSZ substrate and the $\mathrm{Zn}_{3} \mathrm{~N}_{2}$ 
layer, taking into account the epitaxial relationships of Figure $2(\mathrm{G})$, amounts to $-5.1 \%$ (considering a domain phase matching condition of two YSZ unit cells for one $\mathrm{Zn}_{3} \mathrm{~N}_{2}$ cell). Therefore, an in-plane tensile strain in the nucleating $Z_{3} N_{2}$ is expected, explaining the smaller out-of-plane $d_{400}$. Using Equations (1) and (2) we reproduced also in this case the asymmetry of the finite-size interference fringes surrounding the $\mathrm{Zn}_{3} \mathrm{~N}_{2}$ (400) main peak, with the resulting depth-dependent $d_{400}$ shown in the inset of Figure 3(b). Although a higher intensity at lower $2 \theta$ angles is observed too, similarly to sample $E$, the thickness-dependent lattice spacing shows this time a tensile strain that is strongest at the film-substrate interface and that relaxes slowly towards the literature value. This is explained by the intensity contribution of the YSZ (200) reflection coming from the substrate, which has been included in the simulation.

Interestingly, no interference fringes were observed for sample $F\left(\mathrm{Zn}_{3} \mathrm{~N}_{2}(100)\right.$ on $\mathrm{MgO}(100)$, diffractogram not shown here), revealing a loss of $x$-ray coherence along the growth direction and pointing towards a lower structural quality, as will be demonstrated in the following.

A good indication of the crystalline quality of a material is given by the full width at half maximum (FWHM) of XRD rocking curves ( $\omega$ scans). The FWHMs of symmetric reflections contain information about out-of-plane lattice rotations (tilt), whereas the FWHMs of asymmetric reflections (measured in the skew geometry) contain information about both out-of-plane and in-plane lattice rotations (twist). Lee et $a{ }^{54}$ developed a model to fit the FWHMs as a function of their inclination angle $\chi$ with respect to the film surface, in order to evaluate the crystalline quality of GaN, AIN and AIGaN thin films heteroepitaxially grown on the basal planes of sapphire or SiC. Within this model, the FWHM $\Gamma_{h k l}$ of the respective $(h k l)$ reflection is given by

$$
\Gamma_{h k l}=\sqrt{\left(\Gamma_{y} \cos \chi\right)^{2}+\left(\Gamma_{z} \sin \chi\right)^{2}+(2 \pi / L)^{2} / Q_{h k l}^{2}}
$$

where $\Gamma_{y}$ represents the tilt, $\Gamma_{z}$ the twist and $Q_{h k l}=\frac{4 \pi}{\lambda} \sin \theta$ is the magnitude of the scattering vector of the $(h k l)$ reflection. The last term corrects for broadening coming from finite grain sizes, containing the effective coherence length $L$. 
The measured FWHMs of the symmetric and of various asymmetric reflections as a function of $\chi$, for the samples E, F and G are presented in Figure 4. Using Equation (3), and neglecting size effects, it is possible to obtain a good agreement with the experiments for all samples, the extracted values for $\Gamma_{y}$ and $\Gamma_{z}$ being reported in Table II. Generally, an increase of FWHM as a function of inclination angle is observed, indicating a microstructure that is dominated by twist. However, while sample E exhibits a relatively moderate tilt value of $0.3^{\circ}$, comparable to more mature heteroepitaxially-grown materials (e.g. GaN), samples F and G (i.e. the (100)-oriented films) display much larger tilt values of $1^{\circ}$ and $1.6^{\circ}$, respectively.

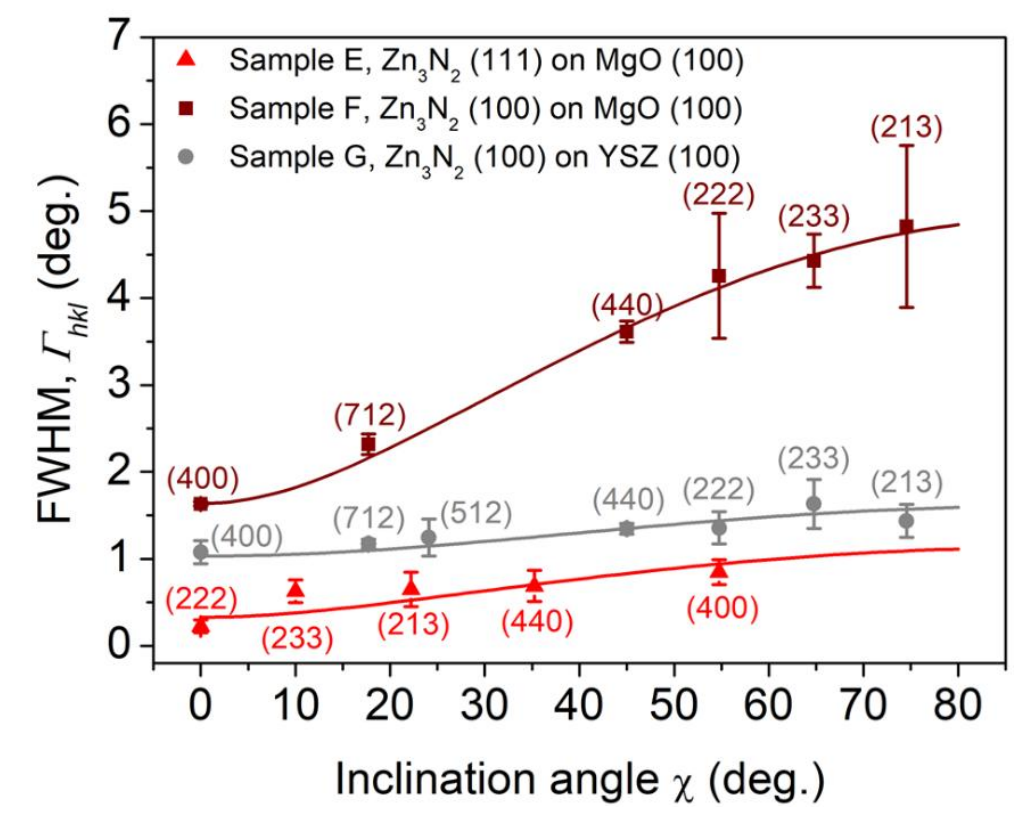

Figure 4: FWHMs of various $\mathrm{Zn}_{3} \mathrm{~N}_{2}$ reflections as a function of inclination angle, measured on a $\mathrm{Zn}_{3} \mathrm{~N}_{2}$ (111) layer grown on $\mathrm{MgO}(100)$ and two $\mathrm{Zn}_{3} \mathrm{~N}_{2}$ (100) layers, grown on $\mathrm{MgO}(100)$ and on YSZ (100) (samples E, F and $G$, respectively). Note that the measurements were done with a fully open detector.

Table II: Extracted tilt and twist values from the fits using Equation (3) and neglecting finite size effects.

\begin{tabular}{ccc}
\hline Sample & $\Gamma_{y}$ (deg.) & $\Gamma_{z}$ (deg.) \\
\hline \hline $\mathrm{E}$ & 0.3 & 1.1 \\
$\mathrm{~F}$ & 1.6 & 4.9
\end{tabular}


Note that contrarily to sample $\mathrm{G}\left(\mathrm{Zn}_{3} \mathrm{~N}_{2}(100)\right.$ on YSZ (100)), sample $\mathrm{F}\left(\mathrm{Zn}_{3} \mathrm{~N}_{2}(100)\right.$ on $\left.\mathrm{MgO}(100)\right)$ shows a dramatic increase of FWHM as a function of $\chi$, with a twist as large as $\Gamma_{Z}=4.9^{\circ}$. To explain this highly in-plane misoriented structure, we should recall the top panel of Figure 1(b), where the large-range $2 \theta / \omega$ scan of sample $F$ is shown. While the diffractogram is largely dominated by $\mathrm{Zn}_{3} \mathrm{~N}_{2}(400)$, there is, however, a small signal at around $31^{\circ}$, corresponding to $\mathrm{Zn}_{3} \mathrm{~N}_{2}(111)$. As explained in Section IIIA, this $Z n_{3} N_{2}(111)$ occurs always at the very initial growth stage when growing on $\mathrm{MgO}(100)$. Consequently, the $\mathrm{Zn}_{3} \mathrm{~N}_{2}$ (100) layer grows on top of (111)-oriented grains, which disturb the subsequent growth compared to a direct nucleation of (100) grains, as on YSZ (100). The large misorientations (tilt and twist) in this sample explain also the loss of $x$-ray coherence along the growth direction, which prevents the appearance of finite size interference fringes, as discussed in Figure 3.

\section{LINEAR THERMAL EXPANSION COEFFICIENT OF $\mathrm{Zn}_{3} \mathrm{~N}_{2}$}

The growth temperature of most epitaxial materials is generally higher than room temperature. Therefore, the knowledge of the linear thermal expansion coefficient of both the substrate and the thin film is necessary to evaluate their lattice mismatches at the actual growth temperature and to understand defects that may be introduced during cooling-down (e.g. cracks). Furthermore, this knowledge can be used to design pseudomorphic heterostructures or to force, on the contrary, a rapid plastic relaxation of the growing film, followed by the overgrowth of relaxed material.

We employed XRD to determine the out-of-plane lattice parameter of $\mathrm{Zn}_{3} \mathrm{~N}_{2}$ as a function of temperature in the range of $300 \mathrm{~K}$ to $700 \mathrm{~K}$, allowing us to extract the linear thermal expansion coefficient. A shift towards lower $2 \theta$ angles for the $\mathrm{Zn}_{3} \mathrm{~N}_{2}(400)$ reflection is clearly observed as the temperature is increased, as shown in Figure 5(a) for a $\mathrm{Zn}_{3} \mathrm{~N}_{2}$ thin film grown on YSZ (100), 
demonstrating the increase of the out-of-plane lattice parameter. Above $700 \mathrm{~K}$ (i.e. $\sim 427^{\circ} \mathrm{C}$ ), no XRD signal could be detected, indicating a degradation/evaporation of the $\mathrm{Zn}_{3} \mathrm{~N}_{2}$ thin films.

Since our $\mathrm{Zn}_{3} \mathrm{~N}_{2}$ thin films are epitaxially attached to their substrates, two extreme cases can be considered for the thermal expansion. If the layer is fully pseudomorphic with a low defect density, its thermal expansion will be driven by the thermal expansion of the substrate, whose influence needs to be corrected for when calculating the linear thermal expansion coefficient of the film. On the other hand, if the layer exhibits a high defect density, it can expand independently from the substrate. For addressing this issue, we measured the thermal expansion coefficient of $Z_{3} N_{2}$ grown on MgO (100) and YSZ (100) substrates, which display very different thermal expansion coefficients (40\% relative difference).

The $d_{400}$ interplanar distances calculated from the measurements on both samples were found to increase linearly as a function of temperature, with an averaged linear thermal expansion coefficient of $(1.5 \pm 0.1) \cdot 10^{-5} \mathrm{~K}^{-1}$. This value is roughly four times larger than thermal expansion coefficients corresponding to III-nitrides such as $\mathrm{AIN}^{55}$ or $\mathrm{GaN}^{56}$ but in the same range as the one of the isostructural $\mathrm{Mg}_{3} \mathrm{~N}_{2}{ }^{47}$ The linear thermal expansion coefficient $\alpha_{T}$ for both samples has been also extracted point-by-point ${ }^{57,58}$ using

$$
\alpha_{T}=\frac{d_{400}(T+\Delta T)-d_{400}(T)}{\frac{1}{2}\left[d_{400}(T+\Delta T)+d_{400}(T)\right] \Delta T},
$$

where $T$ is the temperature and $\Delta T$ the temperature difference between two consecutive points. Generally, the thermal expansion coefficient as a function of temperature follows a well-documented S-behavior, with a fast increase at temperatures close to $0 \mathrm{~K}$ and a saturation at higher temperatures, which can be explained by the successive occupation of acoustic and optical phonons. $55,59,60$ As shown in Figure 5(b), the thermal expansion coefficients of our layers increase only slightly as a function of temperature in the measured range, indicating that the thermal expansion is already in the saturation regime. It should be noted that, despite being grown on two substrates with a large 
difference between their thermal expansion coefficients (MgO: $\sim 1.2 \cdot 10^{-5} \mathrm{~K}^{-1}$, YSZ: $\sim 8 \cdot 10^{-6} \mathrm{~K}^{-1}$ ), ${ }^{61,62}$ both samples show very similar $\alpha_{T}$. This suggest that the substrate influences only marginally the thermal expansion properties of our $\mathrm{Zn}_{3} \mathrm{~N}_{2}$ layers, consistent with their rather low structural quality and a large defect density at the substrate/film interface. Hence, no correction based on the thermal expansion of the substrate was carried out. Besides, it should be noted that this correction would have further required the knowledge of the elastic constants of $Z n_{3} N_{2}$, in particular its Poisson ratio, which have not been yet explored in the literature.

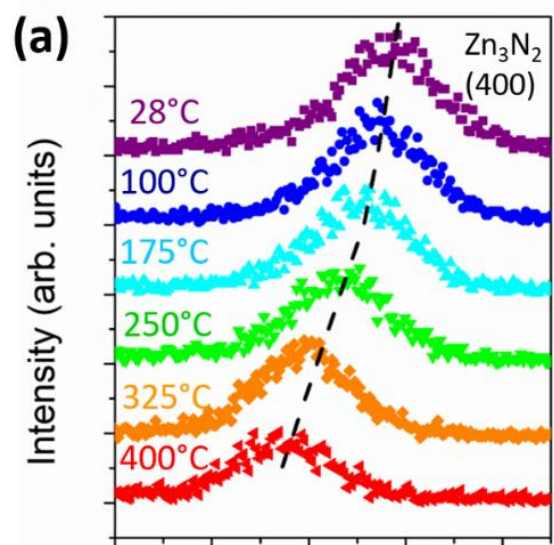

$\begin{array}{lllll}36.2 & 36.4 & 36.6 & 36.8 & 37.0\end{array}$ $2 \theta$ (deg.)

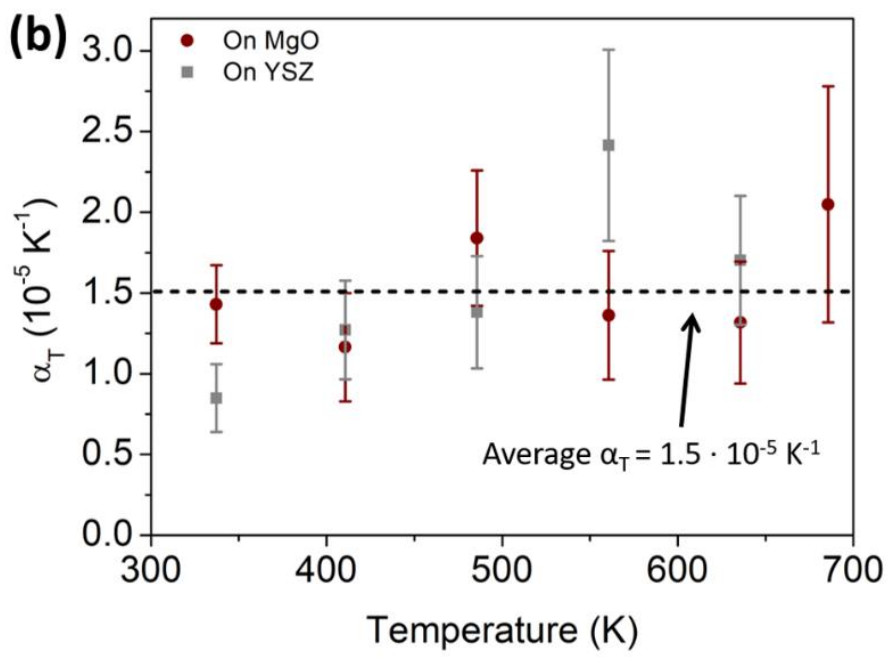

Figure 5: (a) High-temperature XRD of a $\mathrm{Zn}_{3} \mathrm{~N}_{2}$ thin film grown on YSZ (100). (b) Linear thermal expansion coefficient point by point for two $\mathrm{Zn}_{3} \mathrm{~N}_{2}$ films grown on both YSZ (100) and MgO (100), calculated using Equation (4).

\section{ELECTRICAL PROPERTIES OF $Z \mathrm{n}_{3} \mathrm{~N}_{2}$}

The impact of the growth conditions on the electrical transport properties of the $Z n_{3} N_{2}$ thin films was investigated using Hall effect measurements. All layers were found to be n-type and display large electron concentrations, as commonly observed for $\mathrm{Zn}_{3} \mathrm{~N}_{2} \cdot{ }^{27,33,34,37,38,41,42}$ Figure 6(a) shows the electron mobilities and concentrations (measured at room temperature) as a function of $Z_{3} N_{2}$ growth temperature, i.e. of the samples discussed so far. The layers are highly conductive (resistivity $\left.\sim 10^{-3} \Omega \mathrm{cm}\right)$ due to the high electron concentrations in the range of $10^{19}$ to $10^{20} \mathrm{~cm}^{-3}$. The electron 
concentration increases moderately as a function of substrate temperature for the samples $\mathrm{A}$ to $\mathrm{E}$. This may indicate a main donor associated to nitrogen vacancies (or zinc interstitials) and an increased desorption of nitrogen during growth, which is in agreement with the decrease of the growth rate (see Table I). Another possible reason for the increase of electron concentration as a function of substrate temperature may be the enhanced incorporation of residual oxygen at high temperatures (e.g. from the reevaporation of oxides stuck onto the reactor walls). Indeed, oxygen is known to act as an electron donor in $\mathrm{Zn}_{3} \mathrm{~N}_{2}$, ${ }^{42,66}$ eventually explaining the correlation between growth temperature and carrier concentration. Interestingly, all samples exhibit electron mobilities around a value of $150 \mathrm{~cm}^{2} \mathrm{~V}^{-1} \mathrm{~s}^{-1}$, independently of their crystallinity (compare with Figure 1). Indeed, the conduction band of $\mathrm{Zn}_{3} \mathrm{~N}_{2}$ is mainly composed of spherical $\mathrm{Zn} 4 \mathrm{~s}$ and $\mathrm{N} 2 \mathrm{~s}$ states, ${ }^{29}$ making the electron conductivity relatively insensitive with respect to the atomic bond angles, ${ }^{63}$ as opposed to e.g. $\mathrm{Si}$, where $\mathrm{sp}^{3}$ states dominate the conduction band, and the mobility of amorphous material is roughly two orders of magnitude smaller than that of crystalline $\mathrm{Si}^{63}$
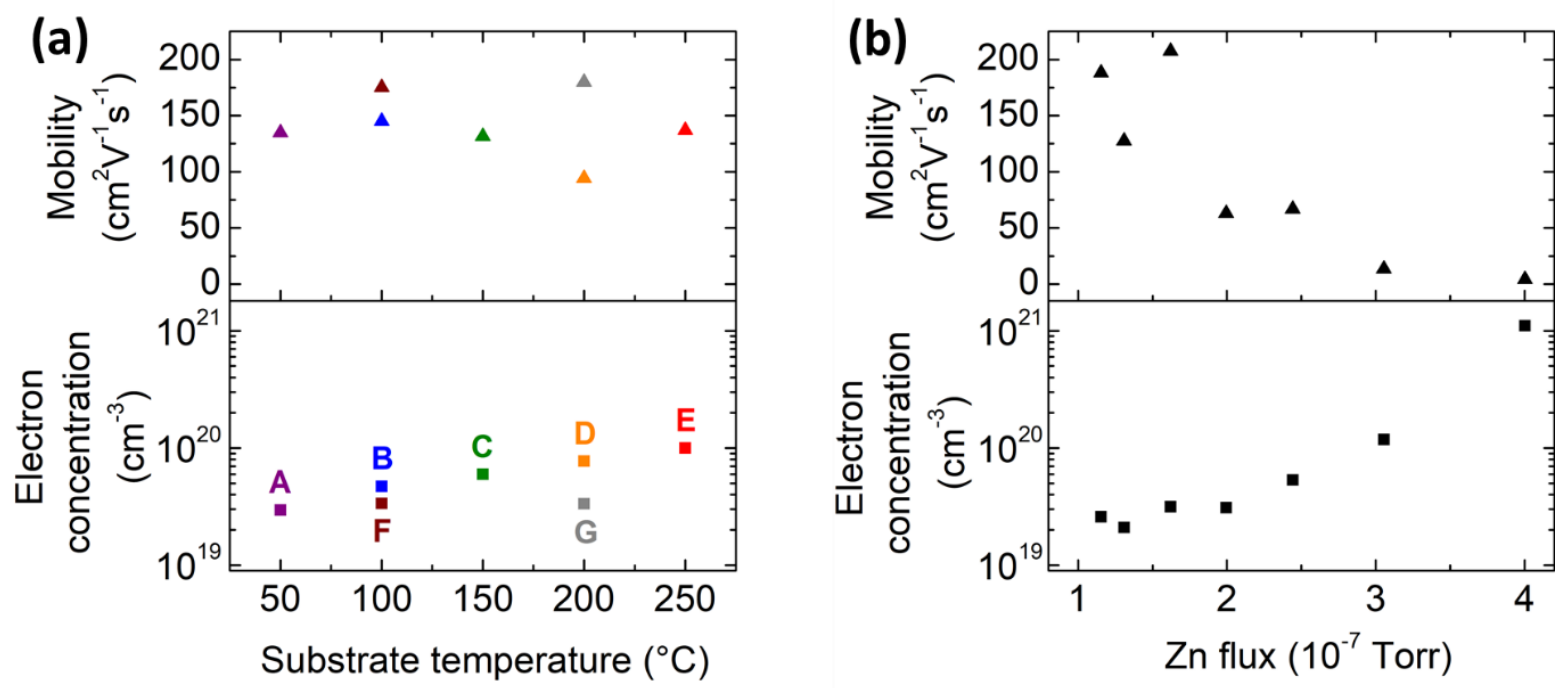

Figure 6: Electron transport properties at room temperature of $Z n_{3} N_{2}$ thin films determined by Hall effect measurements as a function of (a) $\mathrm{Zn}_{3} \mathrm{~N}_{2}$ growth temperature (see Table I) and (b) Zn flux (samples grown at $100{ }^{\circ} \mathrm{C}$ and with $0.85 \mathrm{sccm} \mathrm{N}$ ).

In order to better identify the mechanisms that determine the mobility, we grew another series of $\mathrm{Zn}_{3} \mathrm{~N}_{2}$ thin films on $\mathrm{MgO}(100)$ as a function of $\mathrm{Zn}$ flux, at a substrate temperature of $100{ }^{\circ} \mathrm{C}$ and 
nitrogen flow of $0.85 \mathrm{sccm}$. The results of the Hall effect measurements of this series are presented in Figure 6(b). A strong increase of electron concentration as a function of $\mathrm{Zn}$ flux is observed, with values around $10^{19} \mathrm{~cm}^{-3}$ for the lowest $\mathrm{Zn}$ fluxes, and greater than $10^{21} \mathrm{~cm}^{-3}$ for the largest $\mathrm{Zn}$ fluxes. Again, this tendency would be consistent with a main intrinsic donor associated to nitrogen vacancies or zinc interstitials, being common defects in nitride semiconductors and predicted to be also the most stable defects in $\mathrm{Zn}_{3} \mathrm{~N}_{2}{ }^{64-66}$. Furthermore, a simultaneous decrease of the electron mobility is observed, indicating an increased electron scattering at higher $\mathrm{Zn}$ fluxes. Carrier scattering occurs in general due to lattice phonons, defects and ionized impurities. The strong decrease of electron mobility from ca. 200 to $3 \mathrm{~cm}^{2} \mathrm{~V}^{-1} \mathrm{~s}^{-1}$ with increasing carrier concentration indicates that scattering due to ionized impurities is probably the main mechanism limiting the mobility.

To confirm this statement we plotted the electron mobility as a function of the electron concentration of all $\mathrm{Zn}_{3} \mathrm{~N}_{2}$ thin films grown in this study (Figure 7). Besides demonstrating a sample with a mobility as high as $388 \mathrm{~cm}^{2} \mathrm{~V}^{-1} \mathrm{~s}^{-1}$ (same growth conditions as Sample G, but with a thickness of $175 \mathrm{~nm})$, close to the highest ever reported value for $\mathrm{Zn}_{3} \mathrm{~N}_{2}\left(395 \mathrm{~cm}^{2} \mathrm{~V}^{-1} \mathrm{~s}^{-1}{ }^{36,67}\right)$ a clear anticorrelation between the electron concentration and the mobility is observed, confirming the dominant role of ionized impurity scattering. Hence, a further decrease of electron concentration below $10^{19} \mathrm{~cm}^{-3}$ could, in principle, lead to even higher electron mobilities. Unfortunately, we were not able to grow thin films with an electron concentration below $10^{19} \mathrm{~cm}^{-3}$. Nevertheless, for a given electron concentration, our films show the highest mobilities published so far, suggesting that epitaxial growth and improving crystalline quality still represents a means to enhance the electronic properties of $\mathrm{Zn}_{3} \mathrm{~N}_{2}$ thin films, even if they seem less sensitive to structural defects than in other semiconductors. 


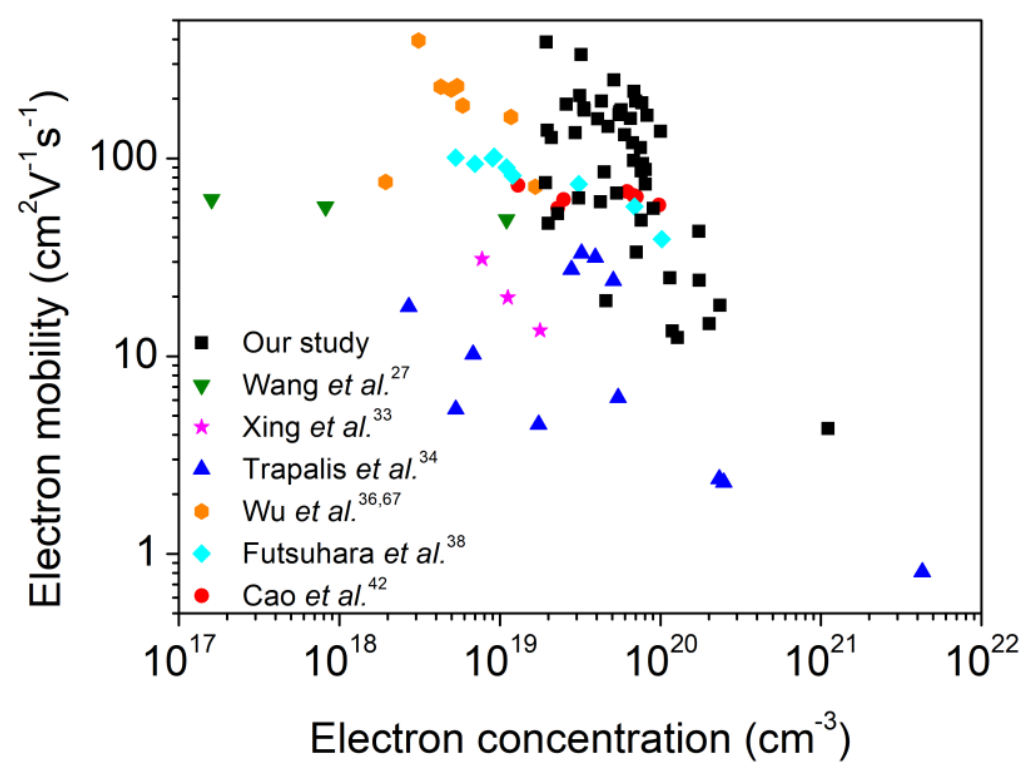

Figure 7: Electron mobility as a function of their concentration for all grown $\mathrm{Zn}_{3} \mathrm{~N}_{2}$ thin films, compared with previous literature work.

We measured the electron transport properties of selected samples with comparatively low electron concentrations (between $2 \cdot 10^{19} \mathrm{~cm}^{-3}$ and $7 \cdot 10^{19} \mathrm{~cm}^{-3}$ ) as a function of temperature between 30 and $300 \mathrm{~K}$, as shown in Figure 8. The electron concentration depends only weakly on the ambient temperature, indicating that all samples are degenerate (see Figure 8(a)), as discussed before. On the other hand, the electron mobilities are constant in a temperature range of ca. 30 to $100 \mathrm{~K}$ and decrease slightly for temperatures above, as shown in Figure 8(b). Using a model applied for polycrystalline transparent conducting oxides (i.e. for degenerate semiconductors), one can deduce the main scattering mechanism by simulating the temperature-dependent mobility. ${ }^{68}$ Within this model, the reciprocal mobility of the thin films is given by

$$
\frac{1}{\mu}=\frac{1}{\mu_{i}}+\frac{1}{\mu_{l}}+\frac{1}{\mu_{g}}
$$

where $\mu_{i}, \mu_{l}$ and $\mu_{g}$ are the limiting mobilities due to scattering by ionized impurities, lattice phonons and grain boundaries, respectively. 
Due to the degeneracy of the investigated films, their Fermi levels lie in the conduction band, leading to a constant $\mu_{i}$ as a function of temperature.$^{68}$ Lattice phonons, on the other hand, are inactive at low temperatures and activated at higher temperatures, showing a $\mu_{l} \propto T^{-1}$ dependency in degenerate thin films. ${ }^{68}$ Grain boundaries, at last, are commonly described by some sort of trap states that create potential barriers for conduction between neighboring crystallites. Applying FermiDirac statistics, the grain boundary scattering-dependent mobility becomes ${ }^{68}$

$$
\mu_{g}=c T^{-1} \exp \left(-\frac{e V_{a}}{k_{B} T}\right)
$$

where $V_{a}$ represents the activation energy related to the potential barrier, $e$ is the elementary charge, $k_{B}$ the Boltzmann constant and $c$ is a fitting constant. Inserting the dependencies of $\mu_{i}, \mu_{l}$ and $\mu_{g}$ in Equation (5) gives

$$
\frac{1}{\mu}=\frac{1}{a}+\frac{T}{b}+\frac{T}{\mathrm{c} \exp \left(-\frac{e V_{a}}{k_{B} T}\right)},
$$

where $a$ and $b$ are fitting constants. We used Equation (7) to reproduce the experimental temperature-dependent mobility shown in Figure 8(b), where the fits are indicated by solid lines.
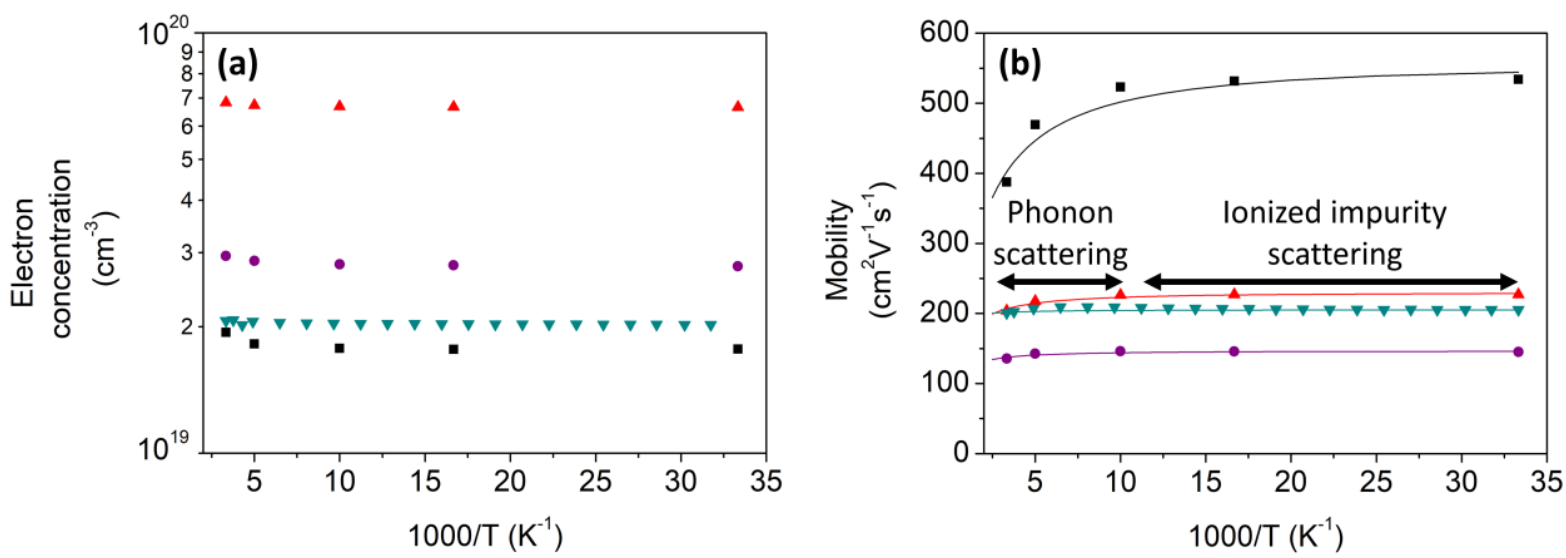

Figure 8: Temperature-dependent Hall effect measurements on selected thin films. (a) Electron concentration and (b) electron mobility as a function of inverse temperature. 
The curves reproduce well the behavior of the electric characteristics. Interestingly, the extracted $V_{a}$, denoting the barrier height due to grain boundaries, is in the order a few $\mu \mathrm{eVs}$, far below $k_{B} T$ at room temperature, indicating an extremely low influence of $\mu_{g}$ on the electrical characteristics in our thin films, as commonly observed in degenerate semiconductors. Indeed, omitting the contribution of $\mu_{g}$ in Equation (5) leads to almost identical fits (curves not shown here), explaining also the electron transport characteristics in the context of Figure 6(a), where the mobility stays roughly constant and independent of the crystallinity of the thin films. Thus, in our thin films the main mechanism limiting the electron mobility is scattering by ionized impurities, with phonon scattering practically contributing at temperatures above $100 \mathrm{~K}$. This result is in agreement with Cao et al., who investigated the electron transport mechanisms of polycrystalline and epitaxial $Z n_{3} N_{2}$ thin films obtained by sputtering. ${ }^{42}$ They found too that the main mechanism limiting the mobility in their degenerate thin films was ionized impurity scattering.

\section{E. OPTICAL PROPERTIES OF $\mathrm{Zn}_{3} \mathrm{~N}_{2}$}

To evaluate the optical band-gap of our $\mathrm{Zn}_{3} \mathrm{~N}_{2}$ thin films, UV-vis-NIR transmission measurements of selected samples were performed at room temperature, allowing thereby the extraction of the absorption coefficient $\alpha$, which was found to be in the $10^{5} \mathrm{~cm}^{-1}$-range close to the band edge. This large $\alpha$ points towards a direct band-gap in $\mathrm{Zn}_{3} \mathrm{~N}_{2}$, consistent with previous literature observations. ${ }^{28-}$ ${ }^{31,34,36-38}$ For direct band-gap semiconductors, a plot of $(\alpha E)^{2}$ against the photon energy $E$ exhibits a linear increase close to the band edge. Extrapolating this linear dependence and identifying its intersection with the horizontal axis reveals the optical band-gap $E_{\text {opt }}$. This so-called Tauc plot is shown in Figure 9(a). All measured samples show optical band-gap energies between 1.05 and $1.37 \mathrm{eV}$, being in agreement with most of the previous literature. ${ }^{10,15,25-38}$ Burstein and Moss ${ }^{43,44}$ described the influence of the carrier concentration in semiconductors on their optical band-gap. The 
displacement of the Fermi level into a parabolic conduction band leads to a band-gap shift $\Delta E$ according to

$$
E_{o p t}=E_{g}+\Delta E n_{e}^{2 / 3}
$$

where $n_{e}$ denotes the electron concentration.
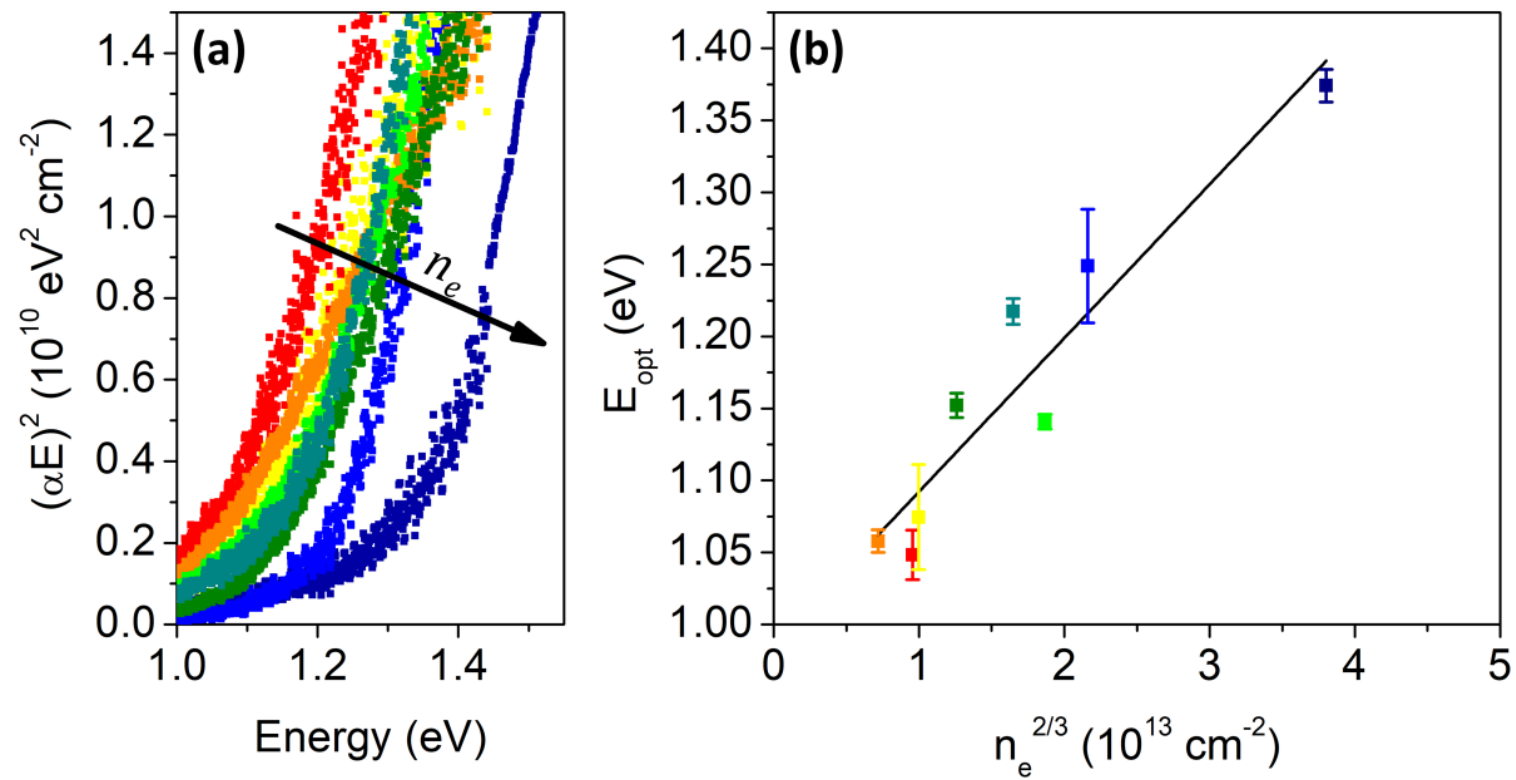

Figure 9: (a) Tauc plot for all measured samples. Note that the change of noise for the right curve is due to a change of detector. (b) Band-gap energy as a function of $n_{e}^{2 / 3}$ at room temperature.

Plotting $E_{\text {opt }}$ as a function of $n_{e}{ }^{2 / 3}$ (see Figure $\left.9(\mathrm{~b})\right)$ reveals a linear increase, whose fit indicates a band-gap energy of $E_{g}=0.99 \mathrm{eV}$ with $\Delta E=1.07 \cdot 10^{-14} \mathrm{eVcm}^{2}$. Suda et al. performed similar measurements on their $\mathrm{Zn}_{3} \mathrm{~N}_{2}$ thin films, grown by metalorganic chemical vapor deposition and MBE, with reported values of $\mathrm{E}_{\mathrm{g}}=1.06 \mathrm{eV}$ and $\Delta \mathrm{E}=1.30 \cdot 10^{-14} \mathrm{eVcm}^{2},{ }^{37}$ in good agreement with our results. These results shine light into the large dispersion of band-gap values appearing in literature, which can be mostly explained by residual doping occurring naturally in $Z n_{3} N_{2}$ thin films (see Figure 7).

\section{CONCLUSIONS}


Epitaxial $\mathrm{Zn}_{3} \mathrm{~N}_{2}$ thin films were grown along the [111] as well as [100] directions on $\mathrm{MgO}(100)$ and YSZ (100), and their orientation could be tuned by varying the growth conditions. Their structural properties, such as epitaxial relationships and crystalline quality have been addressed by in-depth XRD characterization. Interestingly, the structural quality of these films has a low influence on their carrier mobility, being mainly influenced by ionized impurity scattering, with a maximum achieved value in this work of $388 \mathrm{~cm}^{2} / \mathrm{V} \cdot \mathrm{s}$. The degenerate thin films show carrier concentrations between $10^{19}$ and $10^{21} \mathrm{~cm}^{-3}$, leading to a blueshift of the $0.99 \mathrm{eV}$ optical band-gap due to the Burstein-Moss effect. Finally, the linear thermal expansion coefficient of $\mathrm{Zn}_{3} \mathrm{~N}_{2}$ was measured for the first time, which opens a way for the growth optimization of possible epitaxial heterostructures, being an important step towards device fabrication.

\section{Acknowledgments}

We acknowledge support from the Agence Nationale de la Recherche (ANR-17-CE24-0043-01) and Deutsche Forschungsgemeinschaft (GR 1011/36-1) through the project ZONE, as well as Université Côte d'Azûr and "Fédération de Recherche Wolfgang Döblin for providing financial support for Prof. Marius Grundmann visit to CNRS-CRHEA. Further, we thank Ulrike Teschner from the Felix-BlochInstitut für Festkörperphysik for transmission measurements and Mathieu Leroux from CNRS-CRHEA for his numerous suggestions for the report.

\section{Data availability}

The data that support the findings of this study are available from the corresponding author upon reasonable request. 


\section{References}

${ }^{1}$ T. J. Flack, B. N. Pushpakaran and S. B. Bayne, Journal of Elec Materi 45 (2016) 2673.

${ }^{2}$ A. David and L. A. Whitehead, Comptes Rendus Physique 19 (2018) 169.

${ }^{3}$ M. T. Hardy, D. F. Feezell, S. P. DenBaars and S. Nakamura, Materials Today 14 (2011) 408.

${ }^{4}$ B. S. Li, Y. C. Liu, Z. Z. Zhi, D. Z. Shen, Y. M. Lu, J. Y. Zhang, X. W. Fan, R. X. Mu and D. O. Henderson, J. Mater. Res. 18 (2003) 8.

${ }^{5}$ C. Wang, Z. Ji, K. Liu, Y. Xiang and Z. Ye, Journal of Crystal Growth 259 (2003) 279.

${ }^{6}$ Y. Nakano, T. Morikawa, T. Ohwaki and Y. Taga, Appl. Phys. Lett. 88 (2006) 172103.

${ }^{7}$ E. Kaminska, E. Przezdziecka, A. Piotrowska, J. Kossut, P. Boguslawski, I. Pasternak, R. Jakiela and E. Dynowska, MRS Proc. 957 (2006).

${ }^{8}$ C.-W. Lin, Y.-P. Song and S.-C. Chang, Jpn. J. Appl. Phys. 54 (2015) 04DH06.

${ }^{9}$ Y. F. Wang, D. Y. Song, L. Li, B. S. Li, A. Shen and Y. Sui, Phys. Status Solidi C 13 (2016) 585.

${ }^{10}$ B.-S. Li, Z.-Y. Xiao, J.-G. Ma and Y.-C. Liu, Chinese Phys. B 26 (2017) 117101.

${ }^{11} Y$. Jin, N. Zhang and B. Zhang, Materials (Basel, Switzerland) 10 (2017).

${ }^{12}$ Y. Jin, N. Zhang, H. Xu and B. Zhang, Appl. Phys. Lett. 113 (2018) 202401.

${ }^{13}$ A. Allenic, W. Guo, Y. B. Chen, G. Y. Zhao, X. Q. Pan, Y. Che, Z. D. Hu and B. Liu, J. Mater. Res. 22 (2007) 2339.

${ }^{14}$ E. Aperathitis, V. Kambilafka and M. Modreanu, Thin Solid Films 518 (2009) 1036.

${ }^{15}$ C. García Núñez, J. L. Pau, E. Ruíz and J. Piqueras, Appl. Phys. Lett. 101 (2012) 253501.

${ }^{16}$ S. R. Bhattacharyya, R. Ayouchi, M. Pinnisch and R. Schwarz, Phys. Status Solidi C 9 (2012) 469.

${ }^{17}$ M. A. Dominguez, J. L. Pau, M. Gómez-Castaño, J. A. Luna-Lopez and P. Rosales, Thin Solid Films 619 (2016) 261.

${ }^{18}$ M. A. Dominguez, J. L. Pau and A. Redondo-Cubero, IEEE Trans. Electron Devices 65 (2018) 1014.

${ }^{19}$ M. A. Dominguez, J. L. Pau and A. Redondo-Cubero, Semicond. Sci. Technol. 34 (2019) 55002.

${ }^{20}$ M. A. Dominguez, J. L. Pau, A. Orduña-Diaz and A. Redondo-Cubero, Solid-State Electronics 156 (2019) 12.

${ }^{21}$ M. A. Dominguez, J. L. Pau and A. Redondo-Cubero, Solid-State Electronics 171 (2020) 107841.

${ }^{22}$ M.A. Dominguez, J.L. Pau, A. Luna, and A. Redondo-Cubero, Rev. Mex. de Fis. (Revista mexicana de física) 65 (2019) 10.

${ }^{23}$ Kuriyama, Takahashi and Sunohara, Physical review. B, Condensed matter 48 (1993) 2781.

${ }^{24}$ N. Yamada, K. Watarai, T. Yamaguchi, A. Sato and Y. Ninomiya, Jpn. J. Appl. Phys. 53 (2014) 05FX01.

${ }^{25}$ G. Paniconi, Z. Stoeva, R. I. Smith, P. C. Dippo, B. L. Gallagher and D. H. Gregory, Journal of Solid State Chemistry 181 (2008) 158.

${ }^{26}$ M. Gómez-Castaño, J. L. Pau and A. Redondo-Cubero, CrystEngComm 20 (2018) 3666.

${ }^{27}$ Y. Wang, T. Ohsawa, Y. Kumagai, K. Harada, F. Oba and N. Ohashi, Appl. Phys. Lett. 115 (2019) 92104.

${ }^{28}$ P.-C. Wei, S.-C. Tong, C.-M. Tseng, C.-C. Chang, C.-H. Hsu and J.-L. Shen, Journal of Applied Physics 116 (2014) 143507.

${ }^{29}$ S.-H. Yoo, A. Walsh, D. O. Scanlon and A. Soon, RSC Adv 4 (2014) 3306.

${ }^{30}$ C. G. Núñez, J. L. Pau, M. J. Hernández, M. Cervera, E. Ruiz and J. Piqueras, Thin Solid Films $\mathbf{5 2 0}$ (2012) 1924.

${ }^{31}$ S. Simi, I. Navas, R. Vinodkumar, S. R. Chalana, M. Gangrade, V. Ganesan and V. M. Pillai, Applied Surface Science 257 (2011) 9269.

${ }^{32}$ C. García Núñez, J. L. Pau, M. J. Hernández, M. Cervera and J. Piqueras, Appl. Phys. Lett. 99 (2011) 232112.

${ }^{33}$ G. Z. Xing, D. D. Wang, B. Yao, L. F. N. A. Qune, T. Yang, Q. He, J. H. Yang and L. L. Yang, Journal of Applied Physics 108 (2010) 83710. 
${ }^{34}$ A. Trapalis, J. Heffernan, I. Farrer, J. Sharman and A. Kean, Journal of Applied Physics 120 (2016) 205102.

${ }^{35}$ A. Trapalis, I. Farrer, K. Kennedy, A. Kean, J. Sharman and J. Heffernan, Appl. Phys. Lett. 111 (2017) 122105.

${ }^{36}$ P. Wu, T. Tiedje, H. Alimohammadi, V. Bahrami-Yekta, M. Masnadi-Shirazi and C. Wang, Semicond. Sci. Technol. 31 (2016) 10 LT01.

${ }^{37}$ T. Suda and K. Kakishita, Journal of Applied Physics 99 (2006) 76101.

${ }^{38}$ M. Futsuhara, K. Yoshioka and O. Takai, Thin Solid Films 322 (1998) 274.

${ }^{39} \mathrm{M}$. Gómez-Castaño, A. Redondo-Cubero, L. Vázquez and J. L. Pau, ACS applied materials \& interfaces 8 (2016) 29163.

${ }^{40}$ V. Srikant and D. R. Clarke, Journal of Applied Physics 83 (1998) 5447.

${ }^{41}$ M. B. Haider, Nanoscale research letters 12 (2017) 5.

${ }^{42}$ X. Cao, Y. Yamaguchi, Y. Ninomiya and N. Yamada, Journal of Applied Physics 119 (2016) 25104.

${ }^{43}$ E. Burstein, Phys. Rev. 93 (1954) 632.

${ }^{44}$ T. S. Moss, Proc. Phys. Soc. B 67 (1954) 775.

${ }^{45}$ T. Oshima and S. Fujita, Jpn. J. Appl. Phys. 45 (2006) 8653.

${ }^{46}$ D. E. Partin, D. J. Williams and M. O'Keeffe, Journal of Solid State Chemistry 132 (1997) 56.

${ }^{47}$ P. John, H. Rotella, C. Deparis, G. Monge, F. Georgi, P. Vennéguès, M. Leroux and J. Zuniga-Perez, Phys. Rev. Materials 4 (2020).

${ }^{48} \mathrm{P}$. John, P. Vennéguès, H. Rotella, C. Deparis, C. Lichtensteiger and J. Zúñiga-Pérez, Journal of Applied Physics 129 (2021) 95303.

${ }^{49}$ M. Grundmann, T. Böntgen and M. Lorenz, Physical review letters 105 (2010) 146102.

${ }^{50}$ M. Grundmann, phys. stat. sol. (b) 248 (2011) 805.

${ }^{51}$ Triscone, Fivat, Andersson, Decroux and Fischer, Physical review. B, Condensed matter 50 (1994) 1229.

${ }^{52}$ J. Bläsing, A. Krost, J. Hertkorn, F. Scholz, L. Kirste, A. Chuvilin and U. Kaiser, Journal of Applied Physics 105 (2009) 33504.

${ }^{53} \mathrm{C}$. Lichtensteiger, Journal of applied crystallography 51 (2018) 1745.

${ }^{54}$ S. R. Lee, A. M. West, A. A. Allerman, K. E. Waldrip, D. M. Follstaedt, P. P. Provencio, D. D. Koleske and C. R. Abernathy, Appl. Phys. Lett. 86 (2005) 241904.

${ }^{55}$ H. Kröncke, S. Figge, D. Hommel and B. M. Epelbaum, Acta Phys. Pol. A 114 (2008) 1193.

${ }^{56}$ M. Leszczynski, T. Suski, H. Teisseyre, P. Perlin, I. Grzegory, J. Jun, S. Porowski and T. D. Moustakas, Journal of Applied Physics 76 (1994) 4909.

${ }^{57}$ L. Fengchao, Powder Diffr. 8 (1993) 36.

${ }^{58}$ L. Fengchao and Z. Bin, Powder Diffr. 6 (1991) 147.

${ }^{59} \mathrm{H}$. Ibach, phys. stat. sol. (b) 31 (1969) 625.

${ }^{60} \mathrm{H}$. Ibach, phys. stat. sol. (b) 33 (1969) 257.

${ }^{61}$ G. K. White and O. L. Anderson, Journal of Applied Physics 37 (1966) 430.

${ }^{62}$ H. Hayashi, T. Saitou, N. Maruyama, H. Inaba, K. Kawamura and M. Mori, Solid State lonics 176 (2005) 613.

${ }^{63}$ K. Nomura, H. Ohta, A. Takagi, T. Kamiya, M. Hirano and H. Hosono, Nature 432 (2004) 488.

${ }^{64}$ N. Jiang, J. L. Roehl, S. V. Khare, D. G. Georgiev and A. H. Jayatissa, Thin Solid Films 564 (2014) 331.

${ }^{65}$ R. Long, Y. Dai, L. Yu, B. Huang and S. Han, Thin Solid Films 516 (2008) 1297.

${ }^{66}$ Y. Kumagai, K. Harada, H. Akamatsu, K. Matsuzaki and F. Oba, Phys. Rev. Applied 8 (2017).

${ }^{67} \mathrm{P}$. Wu, Epitaxial growth and optical properties of Mg3N2, Zn3N2, and alloys (Victoria, Canada, 2019).

${ }^{68}$ D. H. Zhang and H. L. Ma, Appl. Phys. A 62 (1996) 487. 